\title{
Estimation of radio impulse parameters using the maximum likelihood method*
}

\author{
K. V. Vlasova ${ }^{1}$, V.A. Pachotin ${ }^{2}$, D. M. Klionskiy ${ }^{3}$, and D. I. Kaplun ${ }^{3}$ \\ p_ksenia@mail.ru, VPakhotin@kantiana.ru, klio2003@list.ru, dikaplun@etu.ru \\ ${ }^{1}$ Baltic Fishing Fleet State Academy, 6 Molodezhnaya st., Kaliningrad, Russia \\ ${ }^{2}$ Immanuel Kant Baltic Federal University, 14 A. Nevskogo st., Kaliningrad, Russia \\ ${ }^{3}$ Saint-Petersburg Electrotechnical University "LETI," 5 Prof. Popova st., St. Petersburg, Russia
}

The paper is devoted to the development of an algorithm for resolution and parameter estimation of radio impulses with partially overlapping spectra in the area of their nonorthogonality (the correlation coefficient varies from 0 to 0.9 ). The implementation of the suggested algorithm makes it possible to design filters for resolving frequency-dependent signals and, therefore, to increase the capacity of a communication channel. The maximum likelihood method has been used to obtain analytical expressions and to perform model investigations for frequency resolution of nonorthogonal signals. The dynamic range of signal parameter estimates has been found as a function of signal-to-noise ratio and correlation coefficient. It has been shown that the likelihood functional value in its global minimum allows one to estimate noise variance and the number of radio impulses in a received signal.

Keywords: maximum-likelihood method; radio impulse; resolution; frequency-dependent signal; communication channel; nonorthogonal signals; signal-to-noise ratio

DOI: $10.21469 / 22233792.1 .14 .07$

\section{Introduction}

The paper discusses the problem of estimating parameters of a set of radio impulses with close frequencies. Their spectra partially overlap so that it is difficult to determine the precise number of radio impulses and estimate their parameters using the Rayleigh criterion. In this case, radio impulses are nonorthogonal in the frequency domain so that one can consider several radio impulses orthogonal if their spectra satisfy the Rayleigh criterion. It is necessary to determine amplitudes and frequencies of a set of nonorthogonal radio impulses (when the reception time is known) and their duration.

Modern radio systems function according to the analysis of orthogonal signals. Active pulse radar systems can be used for estimating the parameters of two or even greater number of targets, if their correlation functions do not overlap, i. e., when they are orthogonal relative to the reception moment. It is possible in spectroscopy to separate two spectral lines, if the Rayleigh criterion is satisfied (i.e., orthogonality in the frequency domain is observed). At present, if the orthogonality is not satisfied, this might result in gross errors in signal parameter estimation or a total failure in signal detection.

Nowadays, there are several techniques applied in practice for improving the quality of signal parameter estimation due to a better resolution: Prony technique, MUSIC, etc. [1]. The most widely used techniques are based on the optimal reception theory $[2,3]$. However, the implementation of the aforementioned techniques is connected with a number of difficulties [46]. The problem of signal parameter estimation and resolution within the scope of the optimal reception theory can be handled only when the signals under study are orthogonal [7-12].

\footnotetext{
*The work is supported by Contract No. 02.G25.31.0149 dated 01.12.2015 (Ministry of Education and Science of Russian Federation).
} 
However, when one works in the area of signal nonorthogonality, the logarithm of the likelihood function has a complex structure with a lot of local minima and its minimization is ambiguous.

Let us employ the results of the optimal reception theory, which were developed and extended for the area of signal nonorthogonality. The authors suggest the solution of this problem for nonorthogonal signals using the logarithm of the likelihood function transformed by the system of likelihood equations obtained for energetic signal parameters [13]. As a result of this transform, minimization of the logarithm of the likelihood function proves to be ambiguous. The logarithm of the likelihood function (after transformation) presents a surface in a multidimensional space of nonenergetic signal parameters. The minimum of this surface is the base for estimating both nonenergetic and energetic signal parameters. The minimum of the surface of the logarithm of the likelihood function for a set of signals is the same and, therefore, the term "resolution of similar signals" is not used and one can solve the problem of signal parameter estimation in the area of their nonorthogonality.

The solution of the signal parameter estimation problem depends on the determinant of a correlation matrix when the Rao-Kramer variance estimate is obtained.

\section{Theoretical background}

This section contains the main analytical expressions for an algorithm for processing a set of nonorthogonal (in the frequency domain) radio impulses based on the transformed likelihood functional. Two radio impulses are used to obtain certain expressions for calculating amplitude variances. These variances were used for estimating the application area of the algorithm depending on the correlation coefficient between the signals.

Consider a received signal consisting of $N$ radio impulses in the complex form:

$$
\hat{y}(t)=\sum_{n=1}^{N} \hat{U}_{n} e^{i \omega_{n} t}+U_{n}(t)
$$

where $\hat{U}_{n}$ is the complex amplitude of the $n$th radio impulse; $\omega_{n}$ is the circular frequency of the $n$th radio impulse; and $U_{n}(t)$ is the additive Gaussian noise with the mean value equal to zero, variance equal to $\sigma^{2}$ and the correlation interval equal to $\tau_{k}$.

Using (1), one can obtain the logarithm of the likelihood function:

$$
\ln L(\dot{\boldsymbol{\lambda}})=-\frac{1}{2 \sigma^{2} \tau_{k}} \int_{0}^{T}\left|\hat{y}(t)-\sum_{n=1}^{N} \widehat{\hat{U}}_{n} e^{i \omega_{n} t}\right|^{2} d t=-\frac{1}{2 \sigma^{2} \tau_{k}} \Delta\left(\widehat{\hat{U}}_{n}, \dot{\omega}_{n}\right)
$$

where $\boldsymbol{\lambda}$ is the vector of the estimated parameters of radio impulses; $\Delta\left(\widehat{\hat{U}}_{n}, \dot{\omega}_{n}\right)$ is the likelihood functional; $T$ is the duration of the received signal; and the dashes on top of the variables correspond to the parameters that have to be estimated. The received message $\hat{y}(t)$ corresponds to the mathematical model of a signal with $N$ copies differing by $\dot{\omega}_{1}, \ldots, \dot{\omega}_{N}$. The energy of the message depends on complex amplitudes of radio impulses $\widehat{U}_{n}$ and does not depend on other parameters $\left(\dot{\omega}_{1}, \ldots, \dot{\omega}_{N}\right)$. Therefore, one can consider complex amplitudes to be energetic parameters and frequencies - nonenergetic parameters.

Minimization of (2) is ambiguous due to variability of amplitudes and frequencies of radio impulses, which leads to ambiguity in the solution of the system of likelihood equations in the area of nonorthogonality. The surface of functional (2) has many local minima, which makes it difficult to estimate the parameters of the received message. If it is necessary to obtain one 
minimum of the likelihood surface, Eq. (2) should be transformed in order to exclude energetic parameters from the minimization process.

Amplitude exclusion requires one to differentiate (2) and then solve the corresponding equation. As a result, one will have a system of likelihood equations:

$$
\left.\begin{array}{c}
\int_{0}^{T}\left(\hat{y}(t)-\sum_{n=1}^{N} \widehat{\vec{U}}_{n} e^{i \omega_{n} t}\right) e^{-i \dot{\omega}_{1} t} d t=0 ; \\
\ldots \ldots \ldots \ldots \ldots \ldots \ldots \ldots \ldots \ldots \ldots \ldots \ldots \ldots \ldots \ldots \ldots \\
\int_{0}^{T}\left(\hat{y}(t)-\sum_{n=1}^{N} \widehat{\hat{U}}_{n} e^{i \dot{\omega}_{n} t}\right) e^{-i \dot{\omega}_{N} t} d t=0 .
\end{array}\right\}
$$

These equations can be used to find the amplitudes of $N$ radio impulses, which depend on the estimated frequencies $\omega_{1}, \ldots, \omega_{N}$. Now, designate the amplitudes as $\widehat{\dot{U}} 1_{n}$.

The likelihood functional can also be written in the following form:

$$
\begin{aligned}
\Delta\left(\widehat{\vec{U}}_{n}, \dot{\omega}_{n}\right) & =\int_{0}^{T}\left|\hat{y}(t)-\sum_{n=1}^{N} \widehat{\vec{U}}_{n} e^{i \omega_{n} t}\right|^{2} d t= \\
& =\int_{0}^{T}\left(\hat{y}(t)-\sum_{n=1}^{N} \widehat{\hat{U}}_{n} e^{i \omega_{n} t}\right)\left(\hat{y}^{*}(t)-\widehat{\hat{U}}_{n}^{*} e^{i \omega_{1} t}-\cdots-\widehat{\vec{U}}_{n}^{*} e^{i \omega_{N} t}\right) d t .
\end{aligned}
$$

After certain transformations, one arrives at

$$
\Delta\left(\widehat{\hat{U}}_{n}, \dot{\omega}_{n}\right)=\int_{0}^{T}|\hat{y}(t)|^{2}-\int_{0}^{T}\left(\hat{y}^{*}(t) \sum_{n=1}^{N} \widehat{\hat{U}}_{n} e^{i \dot{\omega}_{n} t}\right) d t
$$

where the asterisk means complex conjugate.

However, system (3) can be used for finding the amplitudes of radio impulses $\widehat{\hat{U}}_{n}$ depending on the frequency estimates $\dot{\omega}_{1}, \ldots, \dot{\omega}_{N}$. These amplitudes can be designated as $\widehat{\hat{U}} 1_{n}$. Now, one can write the transformed likelihood functional

$$
\Delta\left(\dot{\omega}_{n}\right)=\int_{0}^{T}|\hat{y}(t)|^{2}-\int_{0}^{T}\left(\hat{y}^{*}(t) \sum_{n=1}^{N} \widehat{\hat{U}} 1_{n} e^{i \omega_{n} t}\right) d t
$$

depending on only nonenergetic radio impulse parameters, i.e., the estimated frequencies $\dot{\omega}_{1}, \ldots, \dot{\omega}_{N}$. Therefore, the surface will have only one global minimum indicating the estimated frequency values $\dot{\omega}_{1}, \ldots, \dot{\omega}_{N}$. Substituting them in the likelihood system (3), one can estimate the amplitude values $\widehat{\dot{U}}_{n}$.

If the number of radio impulses in the received signal and in the signal model is the same, the likelihood functional (4) determines the noise variance in the received message. However, in practice, the apriori information on the expected number of radio impulses is not always available. This fact can be illustrated using the following example. In communications applications, one can receive two or a greater number of radio impulses with unknown frequencies. The number of radio impulses is also unknown and they have to be resolved. Another example 
is related to radio spectroscopy, where the number of spectral lines is unknown. The spectral lines can be orthogonal or nonorthogonal. These examples confirm the necessity of estimating the number of radio impulses in the received message. The authors suggest an algorithm based on changing the number of signal copies $N$ in the mathematical model and finding the values of the likelihood functional (4) in its minimum.

If the number of signal copies $N$ in the mathematical model is greater than the number of radio impulses in the received message, the amplitudes of extra components are close to zero since they are determined by separate noise maxima. The minimal value of likelihood (4) will be determined by the noise variance.

If the number of signal copies $N$ is smaller than in the received message, the value of the likelihood functional rises dramatically since it determines the noise variance in the received message and the radio impulses which are not included in the model.

Thus, processing the received message requires one to increase the number of signal copies $N$ till the minimum value of the likelihood functional stops decreasing.

Evaluation of the solution quality in the optimal reception theory is based on estimating variances using Rao-Kramer estimates. Consider two radio impulses in a data set starting at the same time point. One can estimate the variance of radio impulse amplitudes in the minimal point of the likelihood functional for $\dot{\omega}_{1}=\omega_{1}$ and $\dot{\omega}_{2}=\omega_{2}$. By computing the elements of the Fisher information matrix according to the expression

$$
J_{i j}=-M\left(\frac{d^{2} \ln L(\dot{\boldsymbol{\lambda}})}{d \lambda_{i} \lambda_{j}}\right)
$$

one can find a new matrix consisting of the elements

$$
J_{i j}=\int_{0}^{T} e^{i\left(\dot{\omega}_{i}-\dot{\omega}_{j}\right) t} d t .
$$

These are complex correlation coefficients between the radio impulses. The diagonal elements of a matrix, which is inverse to the Fisher information matrix, define the variances of radio impulse amplitudes. The inverse matrix has the following form:

$$
\hat{D}_{U}=\frac{A_{i j}}{\operatorname{det} \hat{J}}
$$

where $A_{i j}$ is the algebraic adjunct for the element of the Fisher matrix with the indices $i, j$ and $\operatorname{det} \hat{J}$ is the determinant of the Fisher information matrix.

Thus, the variance of radio impulse amplitudes is determined by det $\hat{J}$ of the Fisher information matrix. In the case of two radio impulses, the amplitude variance will have the following form:

$$
D_{U_{1}}=D_{U_{2}}=\frac{\sigma^{2}}{K\left(1-|\hat{r}|^{2}\right)}
$$

where $K$ is the number of noncorrelated noise samples on the processing interval $T$ and $\hat{r}$ is the normalized correlation coefficient between radio impulses. 
If $|\hat{r}|=0$, the amplitude variance will have the following form:

$$
D_{U_{0}}=\frac{\sigma^{2}}{K}
$$

Now, let us introduce the normalized variance:

$$
D=\frac{D_{U}}{D_{U_{0}}}=\frac{1}{1-|\hat{r}|^{2}}
$$

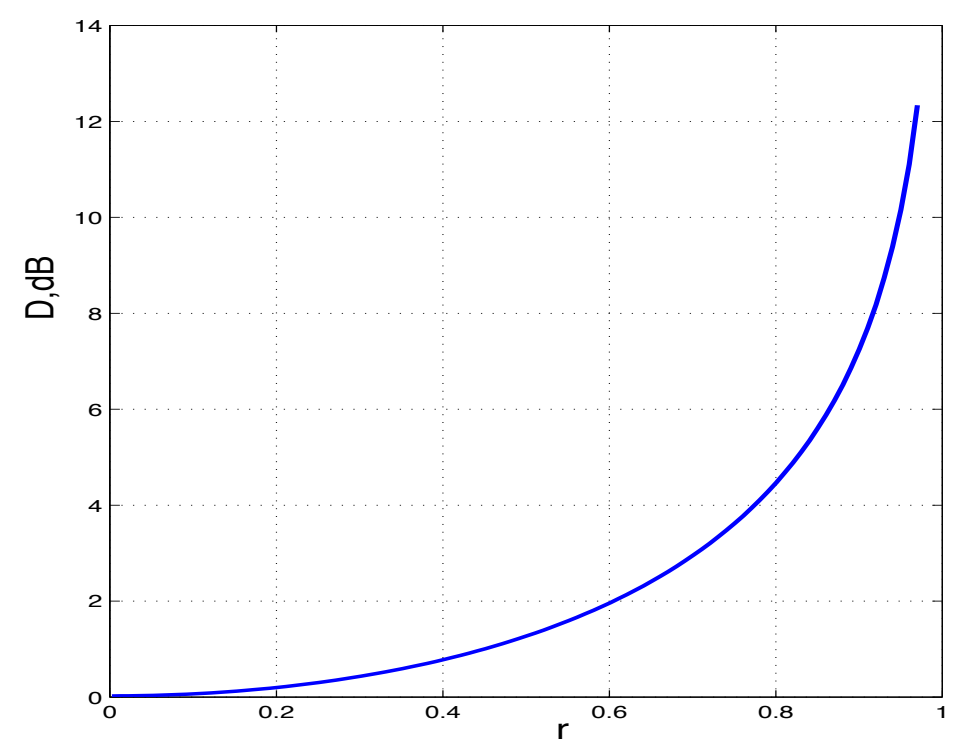

Figure 1 Relative variance vs. normalized correlation coefficient. Relative variance increases by $\sim 7 \mathrm{~dB}$ in the range $|\hat{r}|=0-0.9$; when $|\hat{r}|>0.9$, the relative variance rises dramatically

This expression shows that for $|\hat{r}|=0-0.9$ the changes of the relative variance are approximately $7 \mathrm{~dB}$. In the area where $|\hat{r}|>0.9$, the relative variance grows abruptly as shown in Fig. 1. Thus, if a signal contains two radio impulses, the problem of radio impulse parameter estimation will be solved for the following range of the normalized correlation coefficient: $|\hat{r}|=0-0.9$.

\section{Model studies}

This section is devoted to studying the problem of estimating the parameters of two radio impulses in the area of their nonorthogonality using the maximum likelihood technique and spectral analysis. It will be shown that the maximum likelihood technique can be used for solving this problem in the area of nonorthogonality. The results of the experiments are provided to estimate the quality of the solution depending on the signal-to-noise ratio and correlation coefficient between two radio impulses. The estimation of the noise variance in the received message is illustrated using the dataset (the functional value in its minimum).

Model studies have been carried out for a signal containing two radio impulses combined in the time domain. The radio impulses have the following parameters: amplitudes $U_{1}=$ $=2$ and $U_{2}=1$; initial phases $\varphi_{1}=10^{\circ}$ and $\varphi_{2}=170^{\circ}$; frequencies $f_{1}=2 \mathrm{kHz}$ and $f_{2}$ $=2.08 \mathrm{kHz}$; signal-to-noise ratio is $20 \mathrm{~dB}$; and radio impulse duration is $25 \mathrm{~ms}$. The Rayleigh restriction for radio impulse resolution arises when the frequencies become close by $\Delta f=40 \mathrm{~Hz}$.

Figure 2 shows the normalized correlation coefficient vs. the frequency difference $\Delta f$ between two signals. When $\Delta f=40$ and $80 \mathrm{~Hz}$, the correlation coefficient is equal to zero and the signals 
are orthogonal. The values $\Delta f<40 \mathrm{~Hz}$ correspond to the signal nonorthogonality area. The correlation coefficient values different from zero for $\Delta f>40 \mathrm{~Hz}$ are caused by side lobes of the signal spectrum.

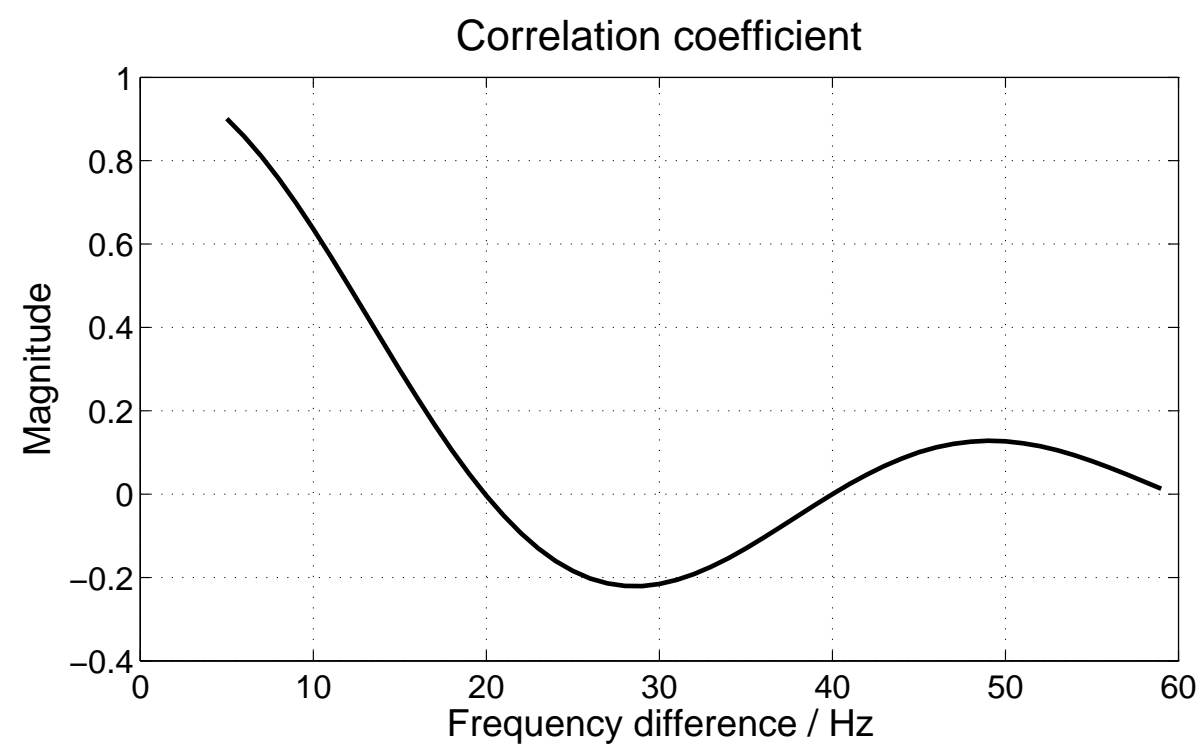

Figure 2 Correlation coefficient between radio impulses. Radio impulse duration is $25 \mathrm{~ms}$. The radio impulses are orthogonal for 40, 80, and $120 \mathrm{~Hz}$. When the radio impulse frequency difference is $10 \mathrm{~Hz}$ and the correlation coefficient is equal to 0.9 , the theoretical estimate of the working area is confirmed

Figure 3 shows the received signal containing two radio impulses with the frequencies $f_{1}$ $=2 \mathrm{kHz}$ and $f_{2}=2.08 \mathrm{kHz}$. According to Fig. 2, these signals are orthogonal since the frequency difference $\Delta f=80 \mathrm{~Hz}$ leads to the correlation coefficient $\hat{r}=0$.

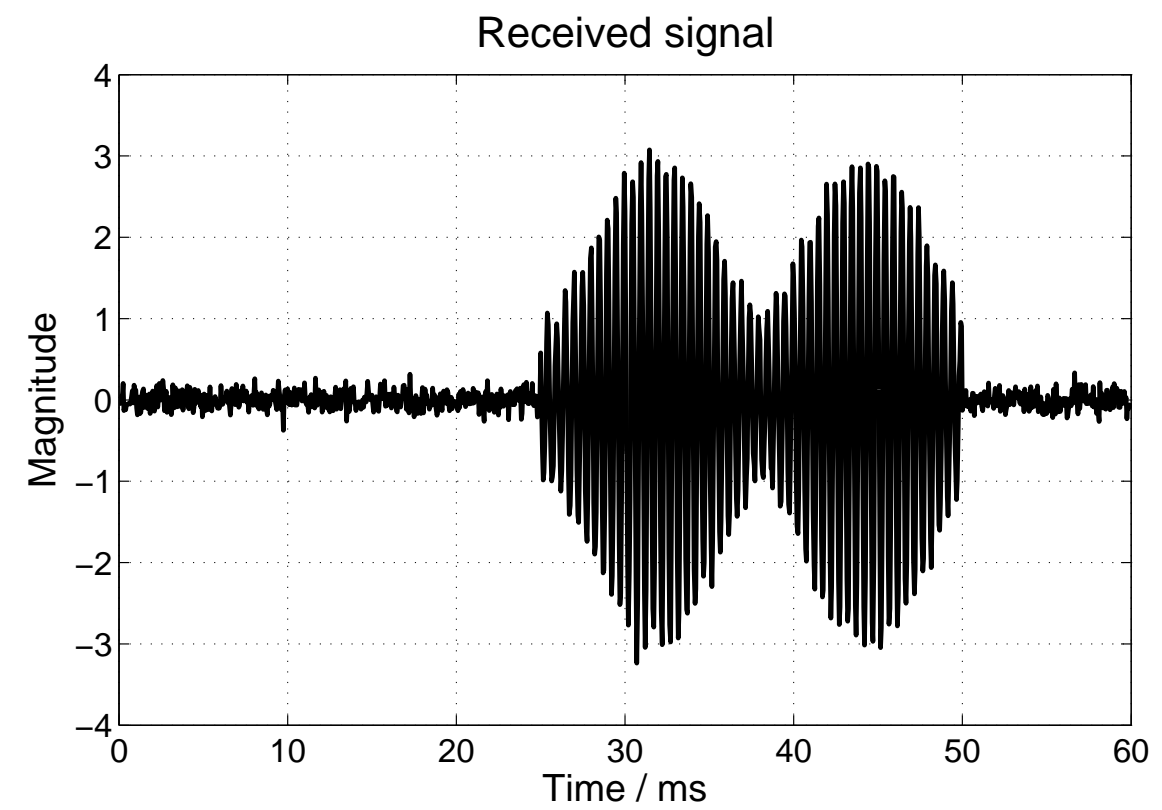

Figure 3 Received signal containing two orthogonal radio impulses combined in the time domain 


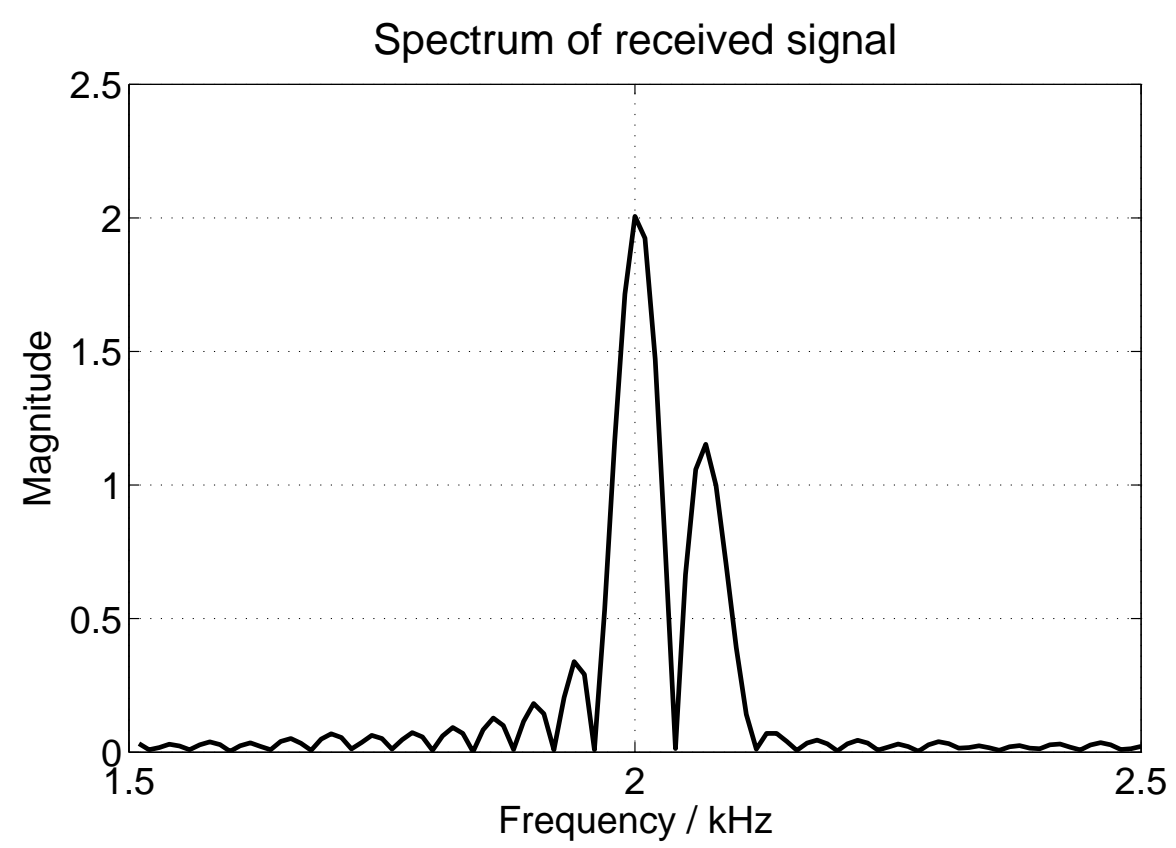

Figure 4 Spectrum of two orthogonal radio impulses combined in the time domain. The maxima of spectral lines determine amplitude and frequency estimates of the radio impulses

The spectra of these two radio impulses is shown in Fig. 4. The side lobes of the first radio impulse $\left(U_{1}=2\right)$ distort the amplitude of the second radio impulse $\left(U_{2}=1\right)$.

Figure 5 shows the surface of the transformed inverse likelihood functional:

$$
\Delta 1=\frac{1}{\Delta\left(\dot{\omega}_{1}, \dot{\omega}_{2}\right)}
$$

The maximum of the functional surface is the only one which determines the unambiguity of the problem solution. The location of the maximum makes it possible to find the values of estimation frequencies $\omega_{1}$ and $\dot{\omega}_{2}$. Their substitution into likelihood equations makes it possible to find the estimates of complex amplitudes of radio impulses. The value of maximum of the likelihood functional allows one to find the noise variance in a received signal. Figures 3-5 illustrate the possibility of obtaining the solution in the area of radio impulse orthogonality.

Figures 6-8 show the possibility of obtaining the solution in the area of radio impulse nonorthogonality. In this case, the radio impulse frequencies are $f_{1}=2 \mathrm{kHz}$ and $f_{2}=2.02 \mathrm{kHz}$. The difference is $20 \mathrm{~Hz}$. Figure 6 shows the received signal.

Figure 7 shows the spectrum of two radio impulses, which makes it difficult to obtain the information on radio impulse parameters.

Figure 8 shows the transformed likelihood functional, which allows one to estimate the radio impulse parameters.

Figure 9 shows the variations of radio impulse magnitude estimates depending on the changes in radio impulse frequencies. The best amplitude estimates can be found when $\Delta f$ $=10 \mathrm{~Hz}$. This corresponds to the correlation coefficient between radio impulses $\hat{r} \sim 0.9$, which fully confirms the theoretical estimate of the working area $(\hat{r}=0-0.9)$ for parameter estimation of two radio impulses.

Figure 10 shows radio impulse frequency estimates vs. their frequency differences. When the signal-to-noise ratio is $\sim 20 \mathrm{~dB}$ and radio impulse duration is $25 \mathrm{~ms}$, the best estimates are obtained for $\Delta f=10 \mathrm{~Hz}$. Thus, one can point out that the suggested technology of radio 


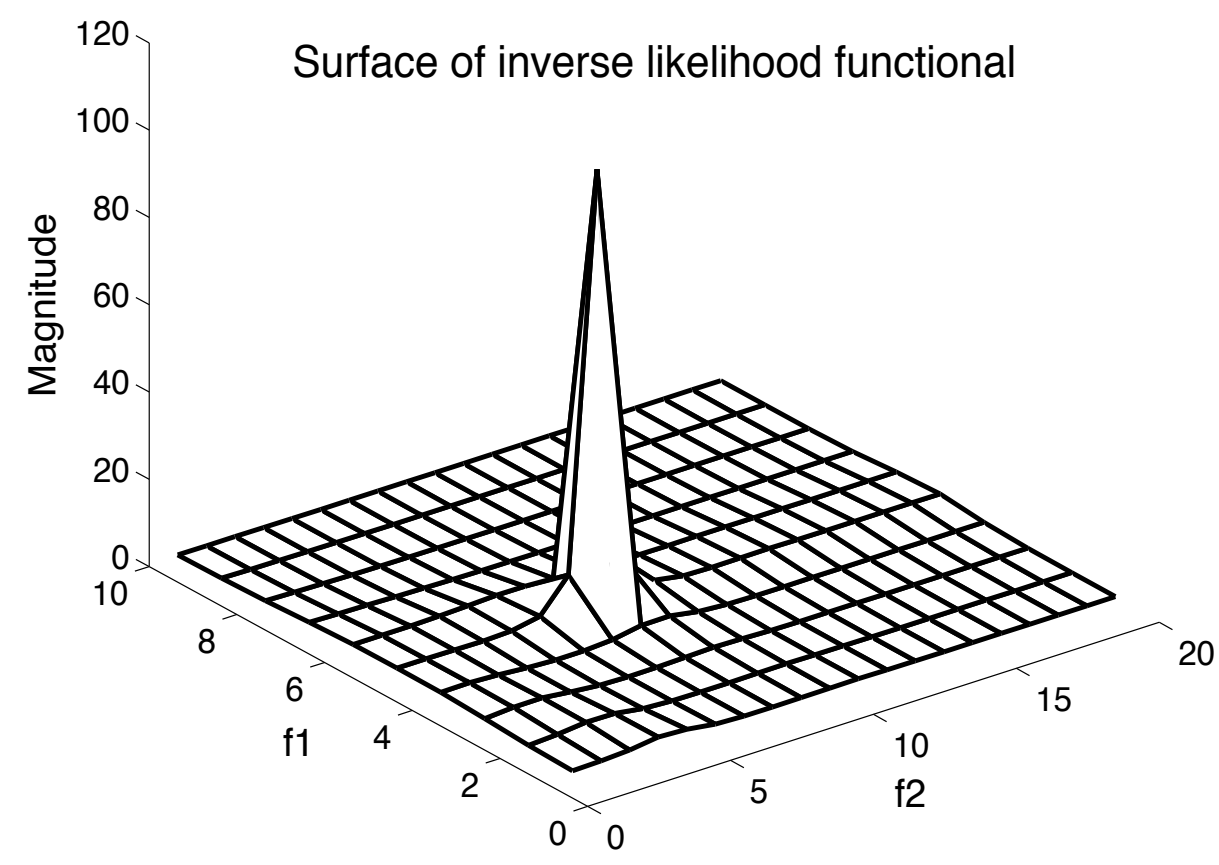

Figure 5 Surface of the inverse likelihood functional. The single maximum determines the parameter estimates of two radio impulses and the term "resolution" is not required. The base width of the maximum of the likelihood functional depends on a signal-to-noise ratio and its maximal value (95.45) determines the estimate of the noise variance in a received signal $(-19.79 \mathrm{~dB}$ relative to 1$)$

impulse parameter estimation is characterized by high resolution. When the signal-to-noise ratio is $20 \mathrm{~dB}$, the resolution of two radio impulses has increased 4 times in comparison with the Rayleigh resolution.

Figure 11 shows the statistics of radio impulse magnitudes depending on the signal-to-noise ratio when the radio impulse frequency is $\Delta f=20 \mathrm{~Hz}$. As can be seen from the figure, the amplitude estimates are quite satisfactory when the signal-to-noise ratio exceeds $0 \mathrm{~dB}$.

Figure 12 shows the statistics of radio impulse frequencies depending on the signal-to-noise ratio for $\Delta f=20 \mathrm{~Hz}$. As can be seen from the figure, radio impulse frequency estimates are quite satisfactory for signal-to-noise ratios exceeding $-5 \mathrm{~dB}$.

Figure 13 illustrates the changes of maxima of the inverse transformed likelihood functional depending on the signal-to-noise ratio in dB. The linear dependence confirms the theoretical suggestion that the noise variance can be estimated on the basis of the maximum of the inverse transformed likelihood functional.

\section{Concluding remarks}

An algorithm for solving the problem of parameter estimation of a set of nonorthogonal radio impulses has been introduced using the maximum likelihood method on the basis of the transformed likelihood functional. Theoretical and practical studies lead to the following conclusions:

- the transformed likelihood functional allows one to solve the problem of resolving and parameter estimation of two or several radio impulses in the area of their nonorthogonality. Application of this technique is efficient for different radio engineering problems and can be used for improving the capacity of communication channels using frequency division multiplexing; 


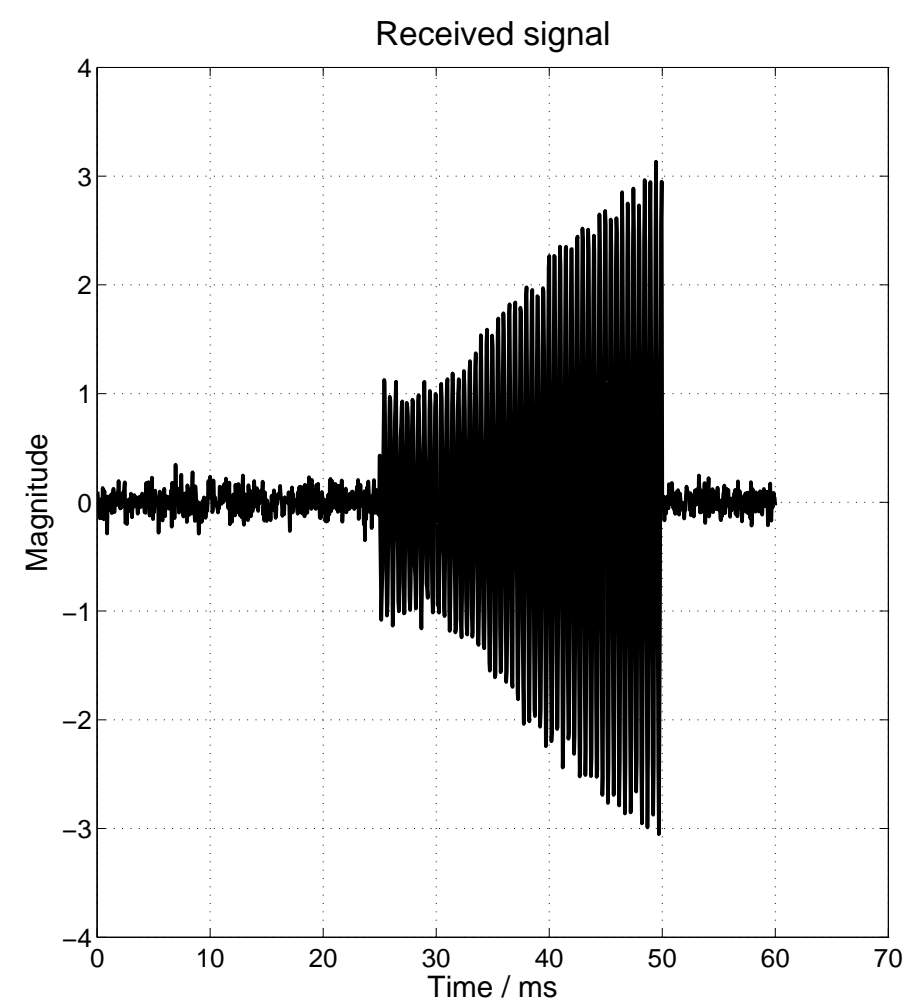

Figure 6 Received signal containing two nonorthogonal impulses combined in the time domain

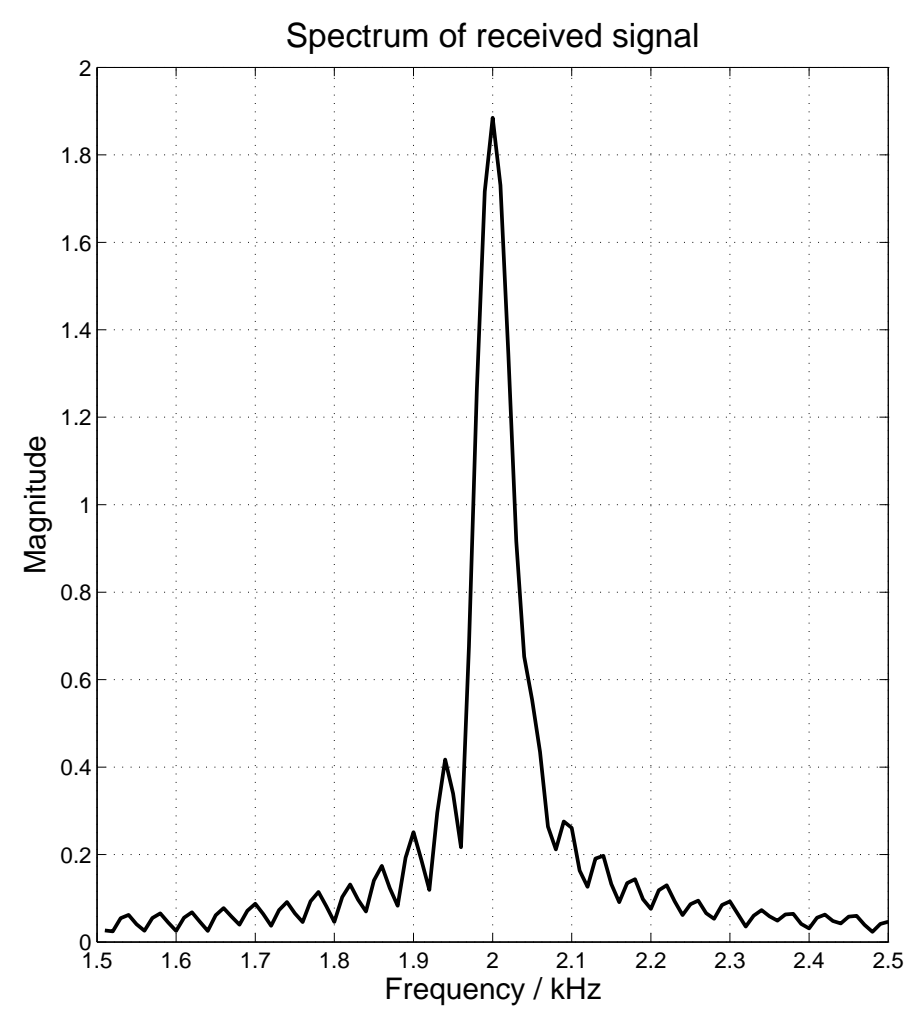

Figure 7 Spectrum of two nonorthogonal radio impulses combined in the time domain 


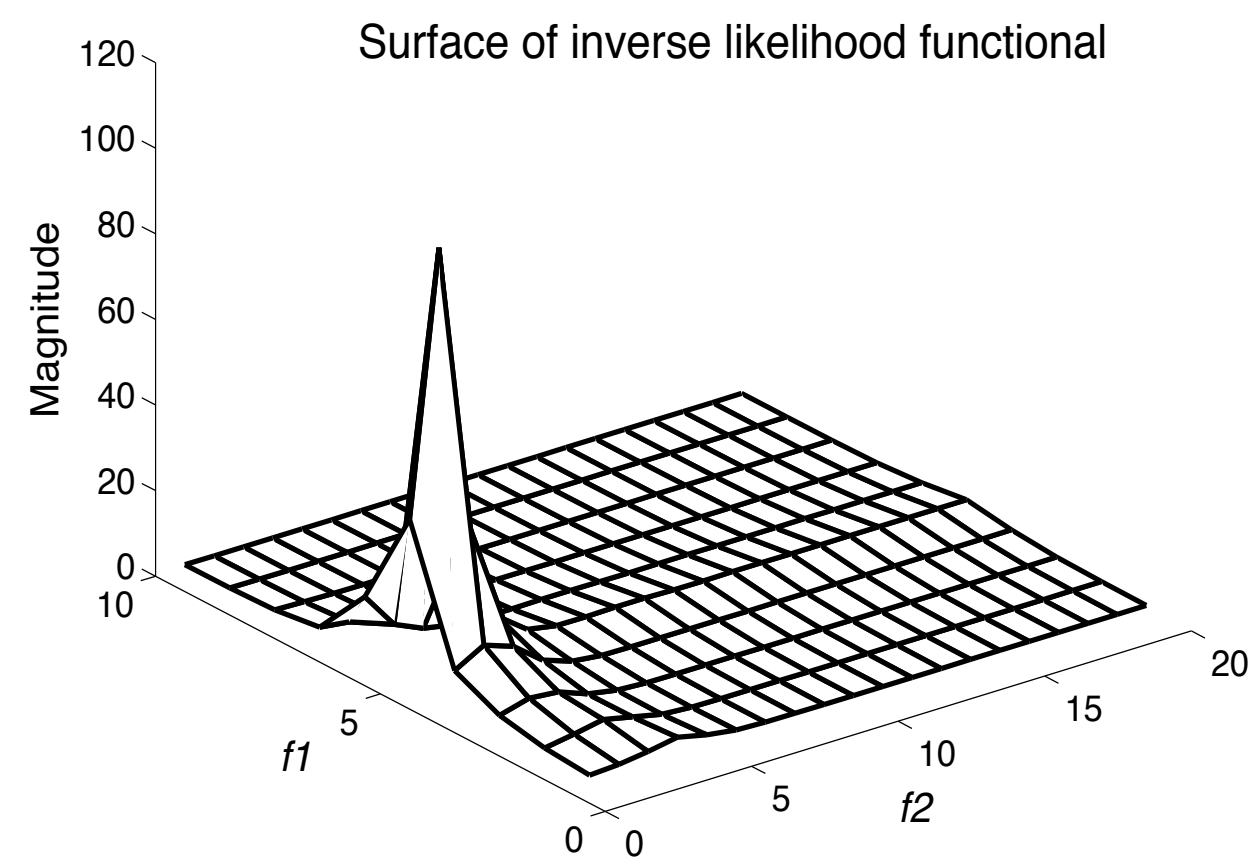

Figure 8 Surface of the inverse likelihood functional obtained in the area of radio impulse nonorthogonality

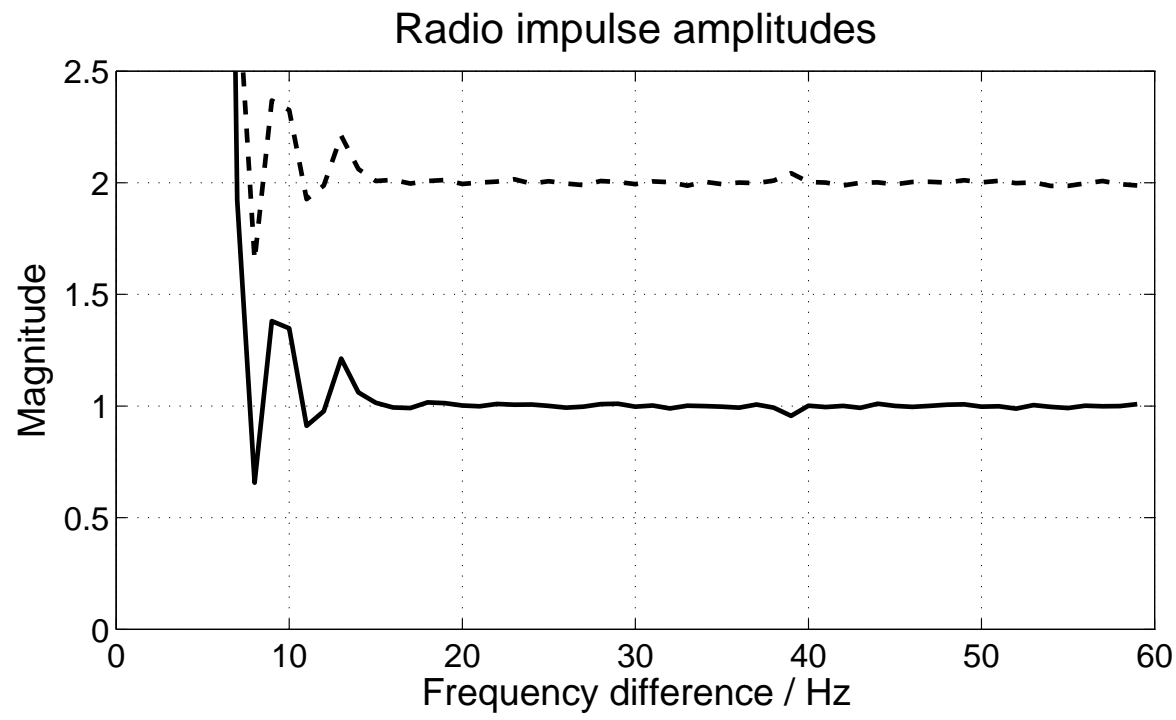

Figure 9 Variation of the amplitude estimates of radio impulses depending on the changes of the frequency differences. The nonorthogonality area of the radio impulses for $\Delta f \leqslant 40 \mathrm{~Hz}$. The best amplitude estimates for radio impulse frequency differences of $10 \mathrm{~Hz}$. Radio impulse resolution has increased 4 times in comparison with the Rayleigh resolution

- the working area for parameter estimation of a set of radio impulses is determined by determinant variations of a correlation matrix of a set of signals. Conditionality of the correlation matrix influences the possibility of resolving a set of signals. In the case of two radio impulses the working area depends on the normalized correlation coefficient in the range $0-0.9$; 


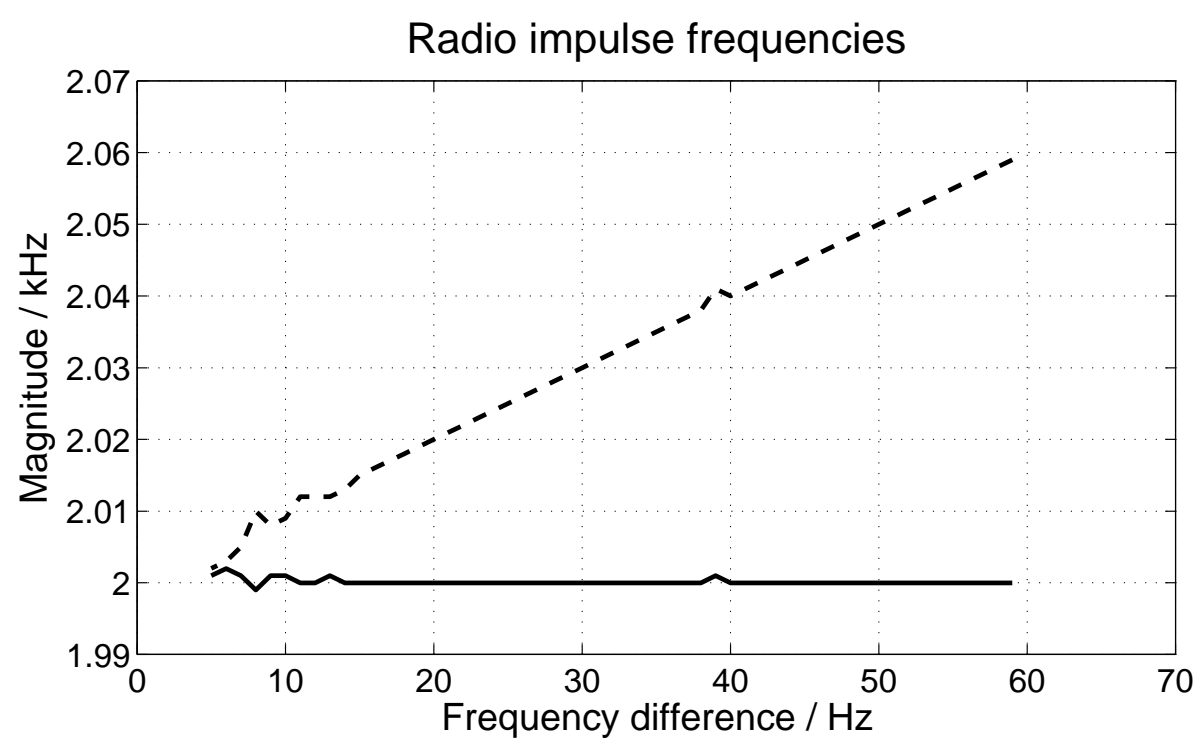

Figure 10 Frequency estimates vs. frequency differences. The area of radio impulse nonorthogonality for $\Delta f \leqslant 40 \mathrm{~Hz}$. The best frequency estimates for radio impulse frequency difference of $10 \mathrm{~Hz}$. Radio impulse resolution has increased 4 times in comparison with the Rayleigh resolution

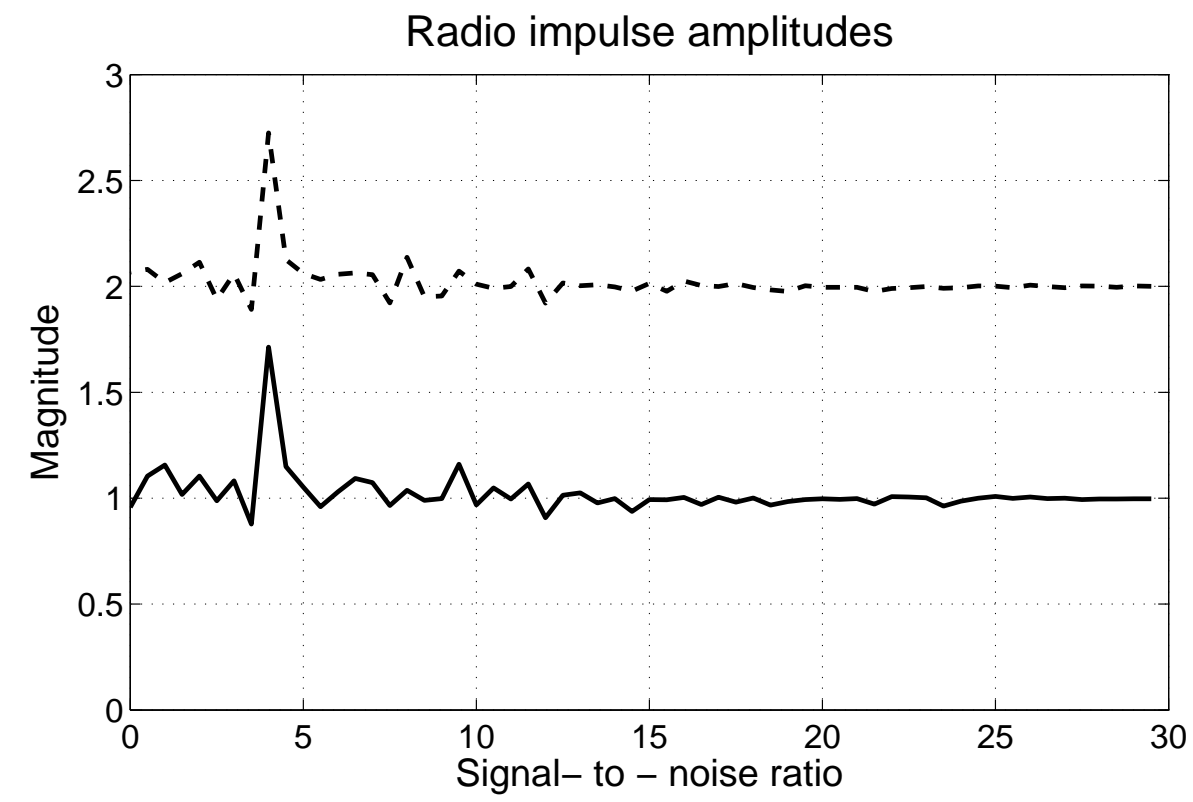

Figure 11 Statistics of radio impulse amplitude estimates. The difference of radio impulse frequencies is $20 \mathrm{~Hz}$ (nonorthogonality area). The estimates are satisfactory for signal-to-noise ratios exceeding $0 \mathrm{~dB}$

- the value of the transformed likelihood functional in its global minimum allows one to estimate the noise variance in a dataset and can be used as a criterion for estimating the number of radio impulses.

\section{References}

[1] Marple, S.L., J. 1986. Digital spectral analysis: With applications. Upper Saddle River, NJ: Prentice-Hall, Inc. 492 p. 


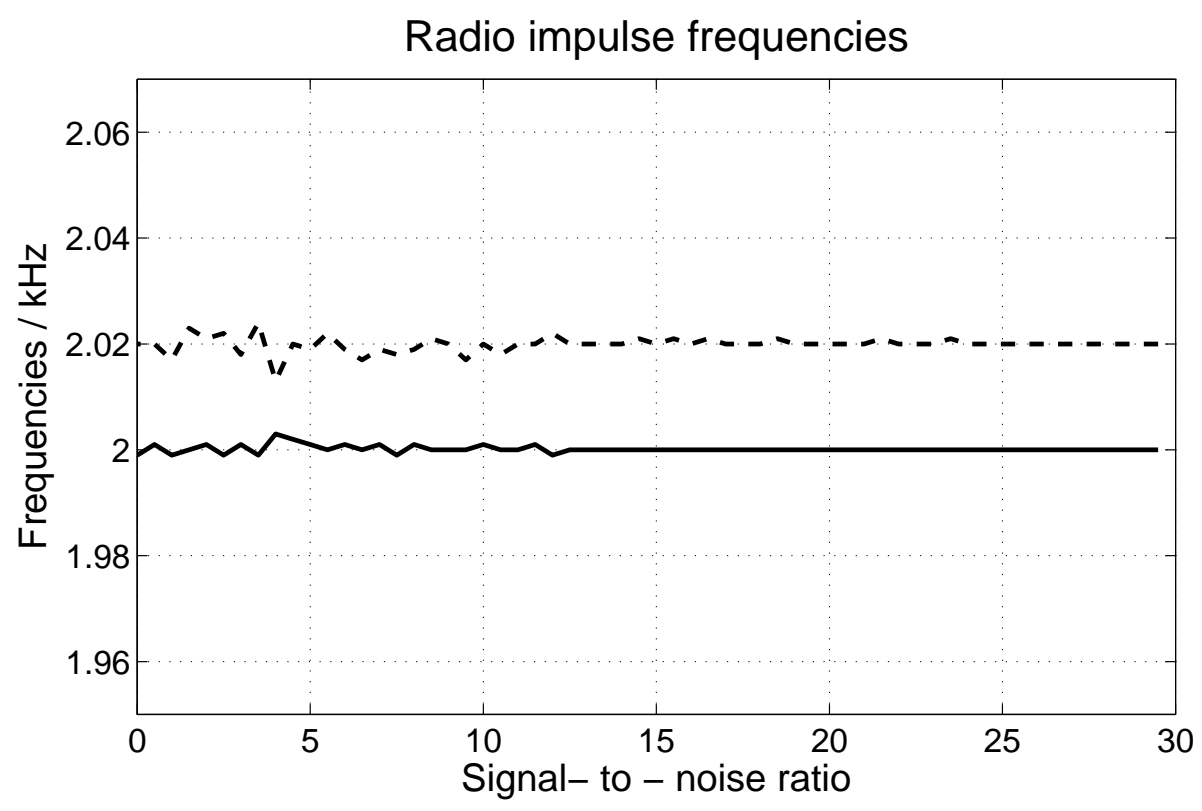

Figure 12 Statistics of radio impulse frequency estimates. The difference of radio impulse frequencies is $20 \mathrm{~Hz}$ (nonorthogonality area). The estimates are satisfactory for signal-to-noise ratios exceeding $-5 \mathrm{~dB}$

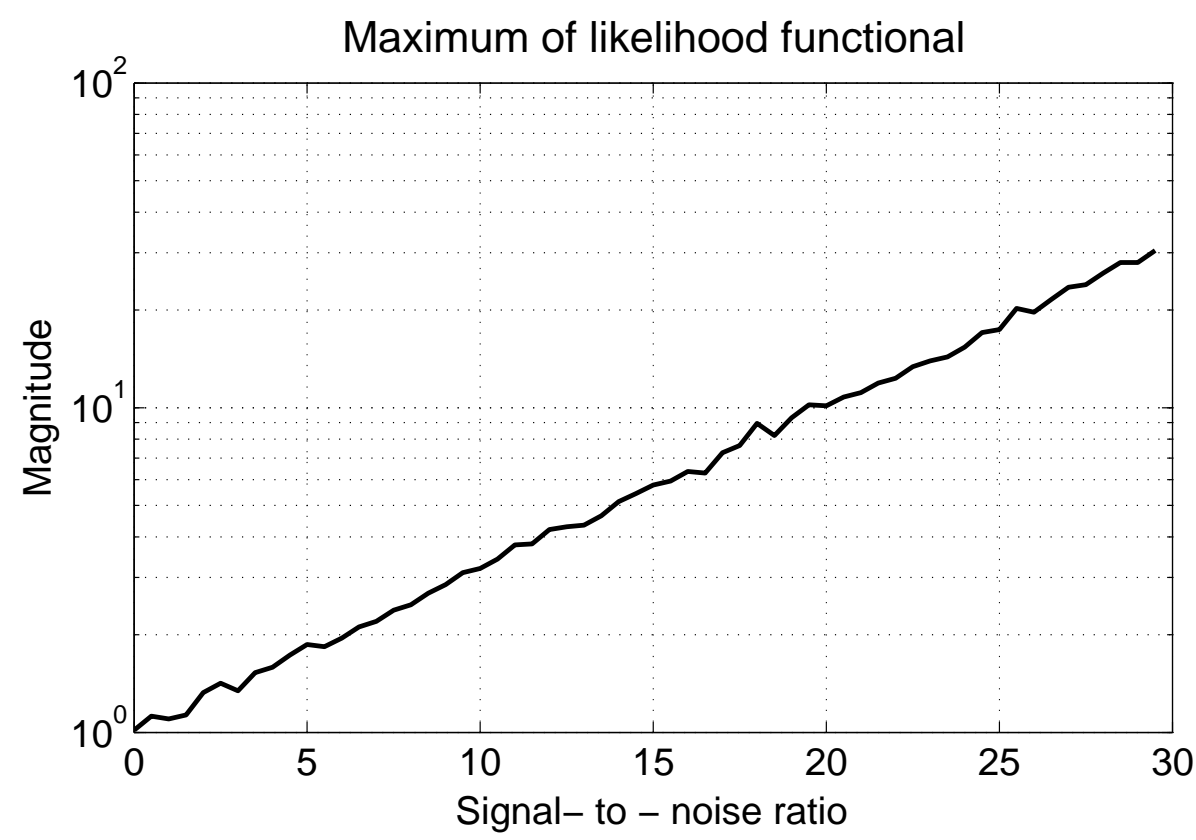

Figure 13 Maximum of the likelihood functional vs. signal-to-noise ratio. The linearity of the dependence allows us to estimate the noise variance in the received message using the maximum of the inverse likelihood functional 
[2] Helstrom, C. W. 1960. Statistical theory of signal detection. International ser. of monographs on electronics and instrumentation. Macmillan. Vol. 9. 364 p.

[3] Tikhonov, V.I. 1983. Optimal signal reception. Moscow: Radio and Communications. 320 p.

[4] Chigov, A. A. 2010. Superrayleigh resolution. Classical approach to the problem. Moscow: Krasand. 104 p. (In Russian.)

[5] Volkov, V. Y., L. S. Turnetskyi, and A. V. Oneshko. 2011. Straight line edge extraction in noisy images. Informatsionno-upravliaiushchie sistemy — Information and Control Systems 4(53):1317.

[6] Volkov, V. Y. 2013. Discrete filtering techniques and problems of image processing in radio engineering observation systems. St. Petersburg: Saint Petersburg University of Telecommunications. 144 p. (In Russian.)

[7] Trifonov, A. P., and Yu. S. Shinakov. 1986. Joint signal distinction and their parameter estimation in the presence of noise. Moscow: Radio and Communication. 246 p. (In Russian.)

[8] Stoica, P., B. Ottersten, M. Viberg, and R. L. Moses. 1996. Maximum likelihood array processing for stochastic coherent sources. IEEE Trans. Signal Proces. 44(1):96-105. doi: http://dx.doi . org/10.1109/78.482015

[9] Troyan, V. N., and Yu. V. Kiselev. 2000. Statistical techniques of processing and interpretation of geophysical data. St. Petersburg: St. Petersburg Polytechnical University. 578 p. (In Russian.)

[10] Perov, A. I. 2003. Statistical theory of radio engineering systems. Moscow: Radio Engineering. $400 \mathrm{p}$.

[11] Zelniker, E. E., and I. V. L. Clarkson. 2003. Maximum-likelihood circle-parameter estimation via convolution. 7th Conference on Digital Image Computing: Techniques and Applications Proceedings. Eds. C. Sun, H. Talbot, S. Ourselin, and T. Adriaansen. Sydney. 509-518.

[12] Babu, P. 2012. Spectral analysis of nonuniformly sampled data and applications. Uppsala, Sweden: Uppsala University. Dissertation.

[13] Pachotin, V.A., V.A. Bessonov, S. V. Molostova, and K. V. Vlasova. 2008. Theoretical fundamentals of optimal signal processing. Kaliningrad. $186 \mathrm{p}$.

Received June 15, 2015

\section{Оценивание параметров радиоимпульса с использованием метода максимального правдоподобия*}

К.В. Власова ${ }^{1}$, В.А. Пахотин ${ }^{2}$, Д. М. Клионский ${ }^{3}$, Д. И. Каплун ${ }^{3}$

p_ksenia@mail.ru, VPakhotin@kantiana.ru, klio2003@list.ru, dikaplun@etu.ru

${ }^{1}$ Балтийская государственная академия рыбопромыслового флота, Россия,

г. Калиниград, ул. Молодежная, 6

${ }^{2}$ Балтийский федеральный университет имени Иммануила Канта, Россия,

г. Калиниград, ул. А. Невского, 14

${ }^{3}$ Санкт-Петербургский государственный электротехнический университет «ЛЭТИ», Россия, г. Санкт-Петербург, ул. Профессора Попова, 5

Статья посвящена разработке алгоритма для разрешения и оценивания параметров радиоимпульсов с частично перекрывающимися спектрами в области их неортогональности (коэффициент корреляции изменяется в пределах от 0 до 0,9). Предложенный алгоритм позволяет проектировать фильтры для разрешения частотно-зависимых сигналов и,

*Работа поддержана контрактом № 02.G25.31.0149 от 01.12.2015 (Минобрнауки России) 
как следствие, появляется возможность повышения пропускной способности канала связи. В статье использован метод максимального правдоподобия для получения аналитических выражений и проведения модельных исследований для частотного разрешения неортогональных сигналов. Динамический диапазон оценок параметров сигналов был определен как функция отношения сигнал/шум и коэффициента корреляции. Показано, что значения функционала правдоподобия в точке глобального минимума позволяют оценить дисперсию шума и количество радиоимпульсов в принятом сигнале.

Ключевые слова: метод максимального правдоподобия; радиоимпульс; разрешение; частотно-зависимый сигнал; канал связи; неортогональные сигналь; отношение сигнал/шyм

DOI: $10.21469 / 22233792.1 .14 .07$

\section{Литература}

[1] Марпл-мл. С.Л. Цифровой спектральный анализ и его приложения / Пер. с англ. - М.: Мир, 1990. 584 с. (Marple S. L. Digital spectral analysis: With applications. - Upper Saddle River, NJ, USA: Prentice-Hall, Inc., 1986. 492 p.)

[2] Хелстром К. Статистическая теория обнаружения сигналов / Пер. с англ. - М.: ИЛ, 1963. 432 c. (Helstrom $C$. W. Statistical theory of signal detection. - International ser. of monographs on electronics and instrumentation. - Macmillan, 1960. Vol. 9. 364 p.)

[3] Тихонов В. И. Оптимальный прием сигналов. - М.: Радио и связь, 1983. 320 с.

[4] Чижсов А. А. Сверхрэлеевское разрешение. Т. 1: Классический взгляд на проблему. - М.: КРАСАНД, 2010. 96 с.; Т. 2: Преодоление фактора некорректности обратной задачи рассеяния и проекционная радиолокация. - М.: КРАСАНД, 2010. 104 с.

[5] Волков В. Ю., Турнецкий Л. С., Онешко А. В. Выделение прямолинейных кромок на зашумленных изображениях // Информационно-управляющие системы, 2011. Вып. 4(53). С. 13-17.

[6] Волков В. Ю. Методы дискретной фильтрации и задачи обработки изображений в радиотехнических системах наблюдения. - СПб.: СПбГУТ, 2013. 144 с.

[7] Трифонов А. П., Шинаков Ю.С. Совместное различение сигналов и оценка их параметров на фоне помех. - М.: Радио и связь, 1986. 246 с.

[8] Stoica P., Ottersten B., Viberg M., Moses R.L. Maximum likelihood array processing for stochastic coherent sources // IEEE Trans. Signal Proces., 1996. Vol. 44. No.1. P. 96-105. doi: http://dx.doi.org/10.1109/78.482015

[9] Троян В.Н., Киселев Ю.В. Статистические методы обработки и интерпретации геофизических данных. - СПб.: Изд-во С.-Петерб. ун-та, 2000. 578 с.

[10] Перов А. И. Статистическая теория радиотехнических систем: Учебное пособие для вузов. М.: Радиотехника, 2003. 400 с.

[11] Zelniker E.E., Clarkson I.V.L. Maximum-likelihood circle-parameter estimation via convolution $/ / 7$ th Conference on Digital Image Computing: Techniques and Applications Proceedings / Eds. C. Sun, H. Talbot, S. Ourselin, T. Adriaansen. - Sydney, 2003. P. 509-518.

[12] Babu P. Spectral analysis of nonuniformly sampled data and applications. - Uppsala, Sweden: Uppsala University, 2012. Dissertation.

[13] Пахотин В. А., Бессонов В. А., Молостова С. В., Власова К. В. Теоретические основы оптимальной обработки сигналов. - Калининград: Изд-во РГУ им. И. Канта, 2008. 186 с. 